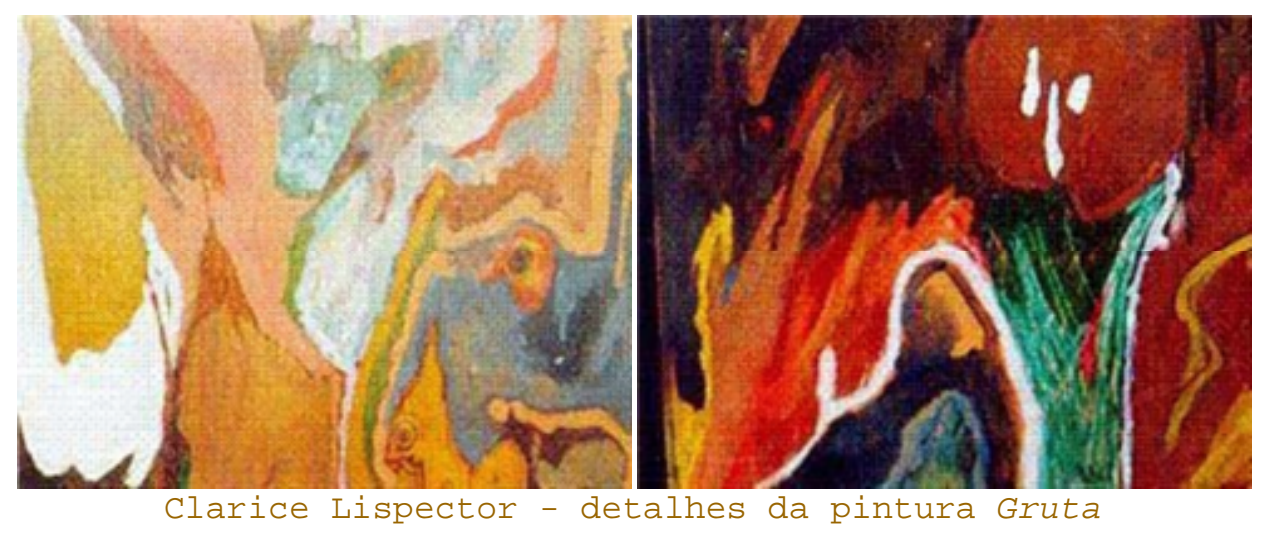

\title{
Clarice Iispector: o dito e o interdito da pintura à ficção
}

\author{
Marcos Antônio de Oliveira(1) \\ Edgar Cézar Nolasco (2)
}

Marcos Antônio de Oliveira é Graduando em Artes Visuais DAC/CCHS/UFMS Bolsista de Iniciação Cientifica - PIBIC/CNPq. Prof. Dr. Edgar Cézar Nolasco - Orientador - DED/CPTL $D L E / C C H S$

Sou fraca, dúbia, há uma charlatã dentro de mim embora eu fale a verdade. E sinto-me culpada de tudo. Eu que tenho crises de cólera, "cóleras sagradas". E não encontro o recolhimento da paz. Por piedade, me deixem viver! eu peço pouco, é quase nada mas é um tudo! paz, paz, paz! Não, meu Deus, não quero ter paz com ponto de exclamação. Quero apenas o mínimo seguinte: paz. Assim, bem, bem devagarzinho ... assim ... quase dormindo ... isto... isto... está quase vindo... Não me assustem, sou assustadíssima.

Clarice Lispector

\section{Resumo}

Este artigo propõe tão-somente fazer uma análise da produção pictural da escritora Clarice Lispector, que se constitui em 16 quadros ao todo, encontrando-se alguns na Fundação Casa de Rui Barbosa, no Rio de Janeiro. Por tal produção resumir-se a uma atividade "amadora" da intelectual, realizada no decorrer do ano de 1975 e meados de 1976, a leitura toma como ponto de 
partida o livro Água viva, por o mesmo apresentar uma narradora-pintora que se propõe a dialogar sobre seu processo de criação pictural-verbal.

Palavras-chave: Clarice Lispector, literatura, pintura.

Clarice Lispector, como todos já sabemos, além de grande escritora, arriscou-se a enveredar pelas artes. Pintou um total de 16 telas "abstratas", cujos títulos são:

Raiva e [reunificação], Gruta, Explosão, Tentativa de ser alegre, Escuridão e luz: centro da vida, Luta sangrenta pela paz, Ao amanhecer, Pássaro da liberdade, Cérebro adormecido, Sem sentido, Medo, (todos de 1975), Eu te pergunto por quê? e sol da meianoite, de 1976, e duas telas sem título (uma sem data e outra de 1975). Dois desses quadros aparecem descritos em Um sopro de vida. (3)

Esses quadros de alguma forma amalgamam parte de sua vida, como a estada fora do país (Berna, Nápoles, Washington) e no país, como o Rio de Janeiro, onde residiu até o fim da vida. Lembramos, conforme atestam suas correspondências, que foi em meio a essas tantas mudanças e viagens que a autora escreveu grande parte de sua obra, visitou museus e teve contacto com grandes artistas, a exemplo de Giorgio De Chirico que a retratou.

Em seu livro Água viva, Clarice Lispector também faz um relato narrativo de sua vida como pintora, onde ela mesma se pergunta e responde sobre suas telas e as critica: "quando estranho uma pintura é aí que é pintura". (4) Podemos entender tal fala da narradora/pintora como uma autocrítica de sua obra como pintora, já que nesse momento a escritora já era consagrada como tal, mesmo que sempre muito criticada, e já se enveredara nas artes plásticas. Vejamos o que diz Lucia Helena Vianna, em texto sobre Clarice Lispector e Frida Kahlo:

Clarice Lispector e Frida Kahlo construíram uma imagem identitária plenamente reconhecida e legitimada socialmente. Atingiram o pódio da consagração nacional em seus países de origem e também internacionalmente pelo mérito excepcional de suas obras, mas também pela singularidade da personalidade rara, com marcas de exotismo, de ambigüidades e excentricidades, pelas histórias de vida incomuns e, por que não, pela capacidade que tiveram de serem elas próprias artífices da imagem que queriam perpetuar de si mesmas. (5) 


\section{Ilustração 1}

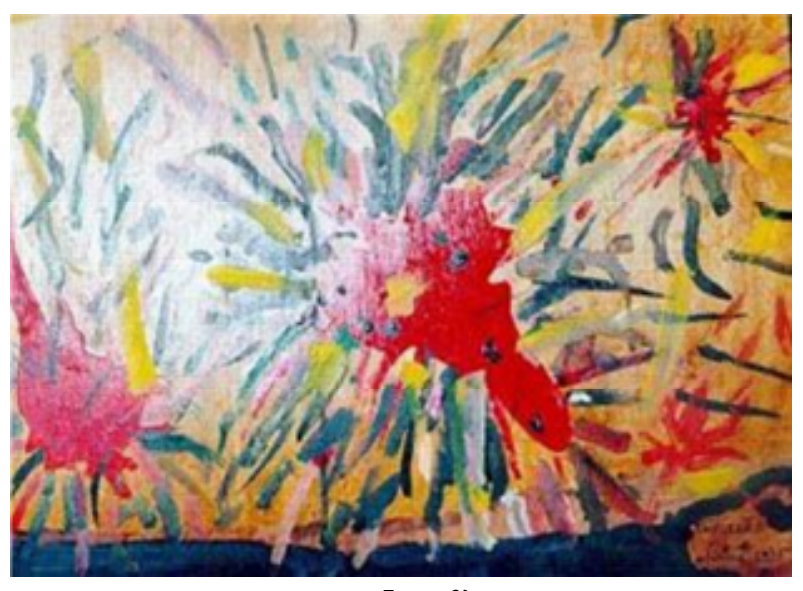

Explosão

Há inúmeras passagens no livro Água viva, que exemplificam a forma de pintar, sofrida e dolorida, que metaforiza o próprio escrever de Clarice, sempre buscando dizer o indizível, ou seja, como a pintura era vista num primeiro olhar ou leitura. Mesmo que Clarice só exercesse a pintura como distração pessoal, o fato é que tais quadros acabaram atingindo a esfera pública, por vários motivos, inclusive porque ela mesma presenteava seus amigos com eles. De fato, o que acaba despertando o interesse da crítica pelas telas é o fato de serem pintadas por Clarice Lispector, o que vem a legitimar a "qualidade" das obras. Quando Clarice depositava ali sua assinatura ela automaticamente dava um valor aos quadros, legitimando-os, por que era a escritora brasileira mais cercada de mistério, quer seja na vida ou na ficção, que os pintara.

o processo de inserção da assinatura do "autor" (não se trata de qualquer autor mas de alguém que, em outro segmento das artes, já tinha reconhecimento autoral) desvencilha a tela do simples prazer da criação, ou seja, coloca a obra num hall de obra de arte, de algo que se torna comercialmente importante. Nesse caso, Compagnon faz uma importante observação da associação entre assinatura e obra criada, quando comenta as relações Duchamp e Andy Warhol:

A obra repousa na sua assinatura, fazendo do artista o lugar da arte. Um quadro é uma imagem, não importa qual, levando uma assinatura. Esta é o equivalente de uma marca de fábrica para os objetos manufaturados: Warhol ou Colgate, na indistinção do que leva uma etiqueta.(6)

Esta passagem de Água viva ilustra o que estamos dizendo, quando Clarice Lispector explica seu ato de pintar, atravessado pela personagem/pintora, entrelaçando-o com o ato criativo da escrita: 
Tente entender o que pinto e o que escrevo agora. Vou explicar: na pintura como na escritura procuro ver estritamente no momento em que vejo - e não ver através da memória de ter visto num instante passado. O instante é este. O instante é de uma iminência que me tira o fôlego. O instante é em si mesmo iminente. Ao mesmo tempo que eu o vivo, lanço-me na sua passagem para outro instante. (7)

Em quase todos os seus quadros, Clarice Lispector, trabalha com elementos que fazem uma alusão, direta ou indiretamente, à morte, à tristeza, ao mistério e ao vazio, termos também recorrentes em sua ficção.

Segundo Lucia Helena Vianna, tal prática se deu por simples hobby: "é dentro desse clima um tanto depressivo que a escritora passa a se dedicar a experiências com a pintura, como passatempo relaxante e terapêutico".(8) Com certeza Clarice não imaginava que suas telas seriam, posteriormente, tão admiradas e valiosas, como sua escrita o foi. Na verdade, o texto-tela funciona como um suplemento ao texto ficcional, ou seja, possibilita a esse um acréscimo de sentido. 0 inverso, talvez, não seria menos possível de ser pensado.

Por mais que Vianna tenha razão com relação ao "simples hobby" não podemos descartar o fato de que tal gesto está carregado de emoções, seleções e sensações pessoais de clarice que são correlatas ao ato de escrever. Exemplifica o que estamos querendo dizer o fato de Clarice, primeiro, escolher o título do quadro e rubricá-lo no corpo da tela para, só depois, pintá-lo, a partir do nome. Daí pensarmos que, escolhido o título, a pintura seria, grosso modo, a cor, a representação, o desenho das emoções e sensações da mulher-artista. Como exemplos da vida, da escrita e da pintura claricianas, Água viva, publicado em 1973, traz uma narradora-feiticeira e pintora que relata sua vida (escrita/pintura) a um intelectual imaginário.

\section{Ilustração 2}

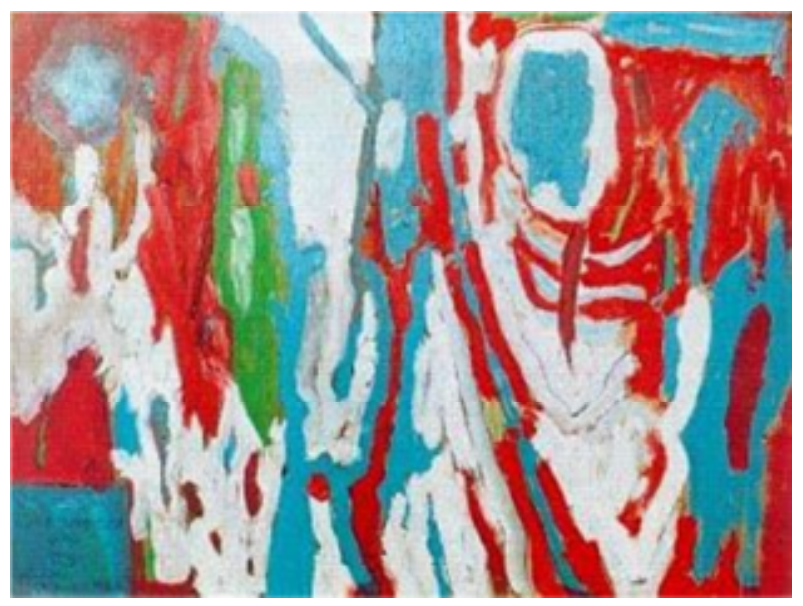

Luta Sangrenta pela Paz 
Registre-se que tal escrita/pintura levada a cabo pela narradora-feiticeira Clarice Lispector ocorreu num contexto histórico no qual as artes passam por mudanças significativas. Nesse sentido, Maria Adélia Menegazzo, em A poética do recorte, lembra-nos que:

\begin{abstract}
Desde meados dos anos 1960, há um reforço dessa prática. As obras então produzidas desarticulam, rompem e corrompem os elementos baseados na lógica racional do discurso realista, questionando sua função numa sociedade dominada pelos meios de comunicação de massa e por sofisticadas técnicas de reprodução. (9)
\end{abstract}

Tal passagem nos remete à época da quebra de regras nos vários segmentos artísticos, o que se dá com o boom do consumo, tornando a arte uma mercadoria destinada também à comercialização. Andy Warhol, por exemplo, usou elementos da mídia como Marilyn Monroe para expor a era consumista que se contrapunha a toda a sofisticação da arte européia, abandonado as regras e os cânones acadêmicos, ou seja, assassinando a obra de arte clássica para que a arte moderna se estabelecesse como tal. Nesse contexto, produtos de massa como a coca-cola expandiu-se para vários países do mundo e houve o surgimento das grandes lojas de departamento, como as Lojas Americanas.

\title{
Ilustração 3
}

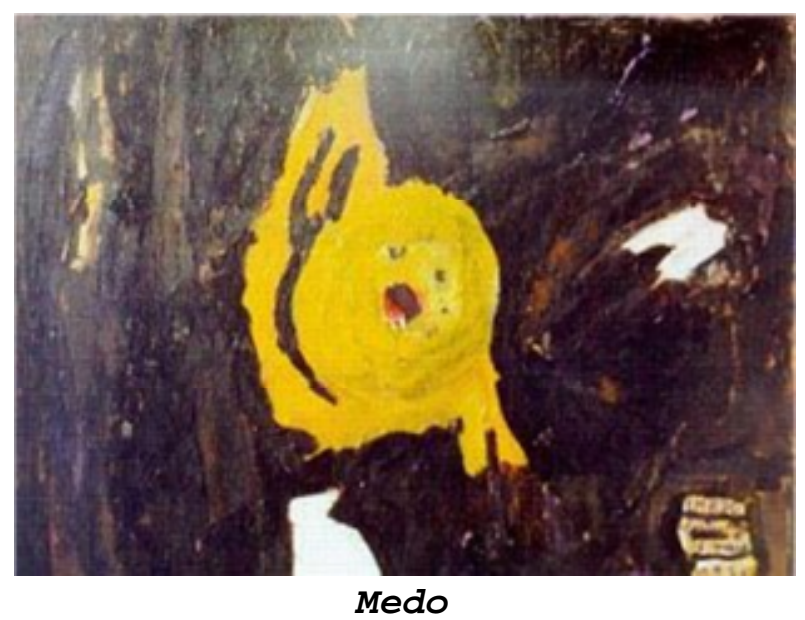

Clarice Lispector parece dialogar com esse contexto, apesar de já haver alguns anos entre o início da discussão e seu período de criação. Livre da obrigação de seguir algumas regras impostas pela sociedade, Clarice se sentiu à vontade para pintar o que quisesse, inserindo em suas telas a realidade de seu próprio dia-a-dia. Era, contudo, uma fase cercada por dúvidas, angústias e medos, já que a escritora se encontrava no auge da carreira literária. 


\section{Ilustração 4}

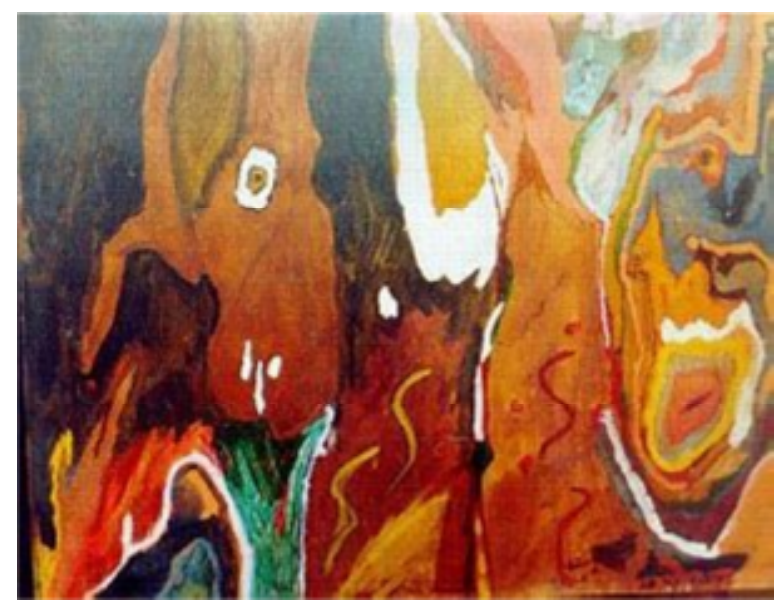

Gruta

A necessidade de produção impecável leva Clarice Lispector a um estado de desordem mental íntima, a um medo que surge imediatamente numa de suas telas, onde ela se encontra num lugar de insegurança, já que em toda a sua trajetória como escritora, ela experimentara tal situação, na busca de afirmação como grande autora.

A pintura, como válvula de escape, libera Clarice dessa pressão psicológica, já que tal trabalho assumido como prazer, como liberdade de expressão, não a colocava na obrigação de ser a melhor das artistas, como seus contemporâneos. Tal liberdade é mostrada por Maria Adélia: "a necessidade de experimentar o novo provocava a urgência em "zerar" experimentos anteriores e se posicionar em relação ao futuro."(10) Esta sem dúvida era a intenção de Clarice Lispector: zerar os experimentos anteriores, livrar-se da experiência de ser uma das melhores, se não a melhor escritora de sua época.

A preocupação de Clarice com suas novas criações em literatura, é demonstrada na obra Um sopro de vida, que é lançada após sua morte, pela amiga Olga Borelli: "Eu queria escrever um livro. Mas onde estão as palavras? esgotaram os significados."(11) Significados que Clarice passa imediatamente a procurar na pintura, uma vez que ela não estaria trabalhando com a forma da palavra dita, mas com a palavra abstrata, dependendo de cada espectador a interpretação. Maria Adélia também mostra essa independência do processo criador na pintura de Clarice:

A arte torna-se autônoma, isto é, livre e independente em relação aos cânones estéticos tradicionais e à realidade do dia a dia, pois agora é capaz de gerar sentido a partir dela mesma, não precisa necessariamente de um tema, e radicaliza a todo o momento a experimentação, os materiais, a posição diante do leitor/espectador. (12) 


\section{Ilustração 5}

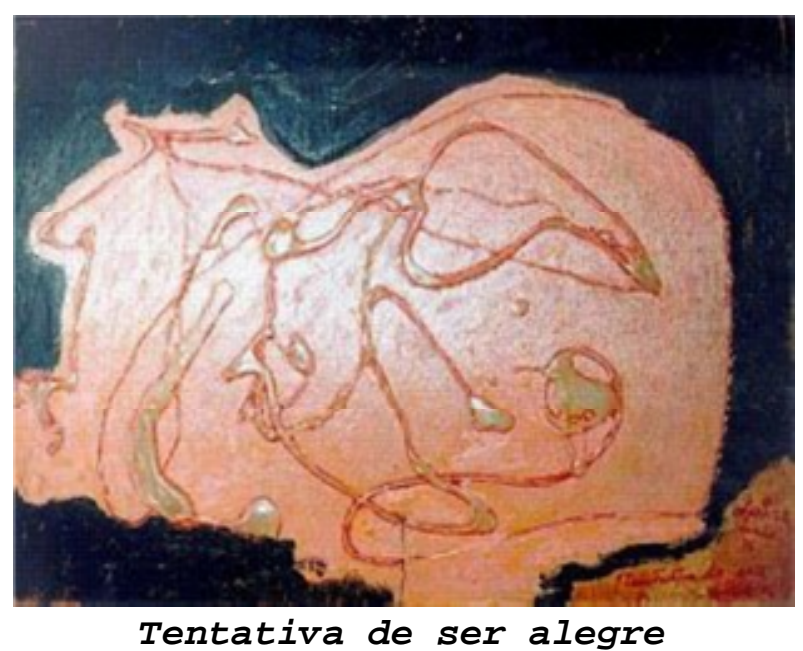

Na tentativa de se ver livre de tais cânones, Clarice se sente mais à vontade no processo de criação pictural que no literário.

A obra póstuma, Um sopro de vida, iniciada em 1974 e concluída em 1977, traz ainda como tema uma escritora/personagem, criada por um suposto escritor/narrador, que era uma artista plástica reconhecida pelo seu trabalho e que tinha imensa vontade de escrever um livro, como já mostramos antes. Lemos tal obra, como o oposto da verdadeira escritora/pintora clarice Lispector que, como é sabido, tinha total consagração literária.

Lucia Helena Vianna, em "O figurativo do inominável", mostra o quanto a escritora se sentia incomodada com a posição de grande escritora que agora ocupava, já que àquela época passara a escrever crônicas semanais para o Jornal do Brasil e atingira um público bem maior do que o alcançado com suas obras literárias. Mas isso Clarice não considerava a melhor das literaturas e sim uma paraliteratura. Sobre isso, Lucia Vianna declara: "O reconhecimento público e a notoriedade, que para a maioria dos artistas traz a feliz sensação de sucesso, nela abriu uma crise pessoal quanto aos rumos de sua escrita."(13)

Tal passagem no texto de Lucia Helena confirma a perturbação que a escritora Clarice Lispector passava no momento de sua criação como pintora de quadros.

Mesmo a partir das afirmações dos estudiosos da escritora, podemos pensar que tal insatisfação quanto a seu sucesso como escritora, não passava de uma encenação da artista clarice Lispector, já que ela buscara em sua vida o tão sonhado êxito. Clarice não só sabia, e muito bem, lidar com as palavras na 
escrita, mas também com as palavras na pintura. Cercada de grandes artistas e conhecedora de hábitos sofisticados, Clarice dominava as técnicas necessárias a uma boa artista da época. Como ela mesma relata em seu livro póstumo, a pintora/personagem Ângela Pralini, da obra Um sopro de vida, era uma mulher de hábitos refinados, preocupada sempre em estar na moda, tendo senso crítico e grande domínio de certas cores e materiais de pintura. Uma vez sendo reconhecida como artista, ela deveria dominar as técnicas de seu fazer, mas não podemos nos esquecer que tal personagem passa pelo cunho autoral de Clarice Lispector, que sempre disse que só pintava por hobby ou para se desligar do mundo exterior. Clarice faz uso do ready-made, estratégia usada por Duchamp, quando deixa de pintar e faz uso de objetos inusitados para compor obras de arte, como a roda de bicicleta e o tamborete (1913), que ele expôes valendo-se do principio de dar finalidades inusitadas a objetos do uso cotidiano, transformando-os em obras de arte. Compagnon descreve esse processo da seguinte forma:

O redy-made é evidentemente iconoclasta, ainda mais na época. Descontextualizando o objeto e dotando-o de um título, ele leva ao cúmulo o nominalismo pictural, quer dizer, a substituição do plástico pelo linguístico na arte, ou do discurso sobre a arte ao recuperável. Duchamp insistia, por outro lado, na indiferença que presidia a sua escolha de objeto. Ele escreve na Boîte Blanche (Caixa Branca): "a exigência de objeto para com o criadorescolhedor não se fundamenta no atrativo exercido sobre este em função de seu gosto, mas sobre a indiferença, na neutralidade, quer dizer, sobre um absenteísmo estético total, uma absoluta 'anestesia' ". (14)

Clarice Lispector valendo-se do redy-made, da re-adequação do material, principia seu processo pictural, utilizando materiais inusitados como suportes, a exemplo da pinho de riga, madeira que à sua época era usada nas melhores construções e em mobiliários. Tais experimentos de leitura estão nos trechos a seguir, quando Ângela/Clarice descreve "Gruta", um de seus quadros, e a técnica de sua pintura ou quando ela brinca com as cores de um suposto vestido que ela teria comprado.

Vivo tão atribulada que não aperfeiçoei mais o que inventei em matéria de pintura. Ou pelo menos nunca ouvi falar desse modo de pintar: consiste em pegar uma tela de madeira - pinho de riga é a melhor - e prestar atenção às nervuras. De súbito, então vem do subconsciente uma onda de criatividade e a gente se joga nas nervuras acompanhando-as um pouco - mas mantendo a liberdade. Fiz um quadro que saiu assim: um vigoroso cavalo com longa e vasta cabeleira loura no meio de estalactites de uma gruta. É um modo genérico de pintar, e, inclusive, não se precisa saber pintar: qualquer pessoa, contanto que não seja inibida demais, pode seguir essa técnica de liberdade.(15) 
Comprei hoje um vestido longo com tons de verde-esmeralda, vermelho-escarlate, branco-gritante, preto-severo, azul-rei, amarelo-doido. (16)

Clarice ainda coloca dúvidas quanto à sua obra, quando em vários momentos de Um sopro de vida justifica sua suposta ineficiência como escritora, como uma fracassada, uma mulher que não sabe lidar com as palavras, quando é na verdade uma suposta inversão de papéis. "Eu tenho vergonha de escrever. Ainda bem que não publico."(17) E ainda: "Dizer a verdade que se encobre de mentiras. Quantas vezes eu minto, meu Deus. Mas é para me salvar. Mentira também é uma verdade, só que sonsa e meio nervosa."(18)

As atitudes tomadas por Clarice Lispector passam pela encenação que ela viveu em quase toda a sua vida, cercada por culpa, medo e insegurança, enquanto escritora iniciante: uma vida entranhada em seus personagens, onde já não existiam limites entre o real e o ficcional. Por isso, clarice Lispector era e continua sendo um enigma.

\section{Resumen}

Este ensayo propone únicamente hacer un análisis de la obra pictórica de la autora Clarice Lispector, que consiste en 16 cuadros en su totalidad, algunos de los cuales se encuentran en la Fundação Casa Rui Barbosa, en Rio de Janeiro. Puesto que tal obra constituye una actividade de "aficionada" de la intelectual, realizada durante el año 1975 y a mediados de 1976, la lectura toma como punto de partida el libro Água viva, que, a su vez, presenta una narradora-pintora, que se propone dialogar sobre su proceso de creación pictórica-verbal.

Key-words: Clarice Lispector, literatura, pintura.

\section{Notas}

(1) Este trabalho é parte integrante de uma pesquisa maior que o autor desenvolve como bolsista da PROPP/PIBIC/UFMS.

(2) Orientador do trabalho "Clarice Lispector: o dito e o interdito da pintura à ficção" .

(3)

http://br.geocities.com/claricegurgelvalente/14_pinturas.htm consultado em 25 de agosto de 2006 .

(4) Lispector, Água viva. p.76.

(5) Tinta e sangue: o diário de Frida Kahlo e os "quadros" de Clarice Lispector. p. $2-3$.

(6) COMPAgnon, os cinco paradoxos da modernidade. p. 97. 
(7) LISPECTOR, Água viva. p. 69.

(8) Tinta e sangue: o diário de Frida Kahlo e os "quadros" de Clarice Lispector. p. 4 .

(9) MENEGAzzo, A poética do recorte. p. 15.

(10) MENEGAZzo, A poética do recorte. p. 21.

(11) LISPECTOR, Um sopro de vida. p. 12.

(12) MENEgAzZo, A poética do recorte. p. 21.

(13) VIANA, O figurativo do inominável: os quadros de Clarice (ou restos de ficção). In: ZILBERMAN, Clarice Lispector: a narração do indizível. p. 49.

(14) COMPAGNON, os cinco paradoxos da modernidade. p. 93.

(15) LISPECTOR, Um sopro de vida. p. 49-50.

(16) LISPECTOR, Um sopro de vida. p. 131.

(17) LISPECTOR, Um sopro de vida. p. 94.

(18) LISPECTOR, Um sopro de vida. p. 61.

\section{Bibliografia}

BORELLI, Olga. Clarice Lispector: esboço para um possível retrato. Rio de Janeiro: Nova Fronteira, 1981.

COMPAGNON, Antoine. Os cinco paradoxos da modernidade. trad. de Cleonice P. Mourão, Consuelo F. Santiago e Eunice D. Galéry. Belo Horizonte: Editora UFMG, 1996.

JAMESON, Fredric. Pós-modernismo. A lógica cultural do capitalismo tardio. trad. Maria Elisa Cevasco. São Paulo: Ática, 2004.

LISPECTOR, Clarice. Água viva. Rio de Janeiro: Rocco, 1998.

1978. , Um sopro de vida: pulsações. Rio de Janeiro: Nova Fronteira,

MENEgAzzo, Maria Adélia. A poética do recorte: estudo de literatura brasileira contemporânea. Campo Grande: Ed. UFMS, 2004 .

NOLASCO, Edgar Cézar. Restos de ficção: a criação biográfico-literária de Clarice Lispector. São Paulo: Annablume, 2004.

Annablume, 2001 .

ORTIZ, Renato. Mundialização e cultura. São Paulo: Brasiliense, 2003. 
VIANNA, Lucia Helena. Tinta e sangue: o diário de Frida Kahlo e os "quadros" de Clarice Lispector. Revista Estudos Feministas. jun 2003 , vol. $11, \mathrm{n} .1, \mathrm{p} .71-87$.

, O figurativo inominável: os quadros de clarice (ou restos de ficção). In: ZILBERMAN, Regina et al. Clarice Lispector: a narração do indizível. Porto Alegre: Artes e Ofícios; EDIPUC; Instituto Cultural Judaico Marc Chagal, 1998. p. 49-64.

\section{Ilustrações}

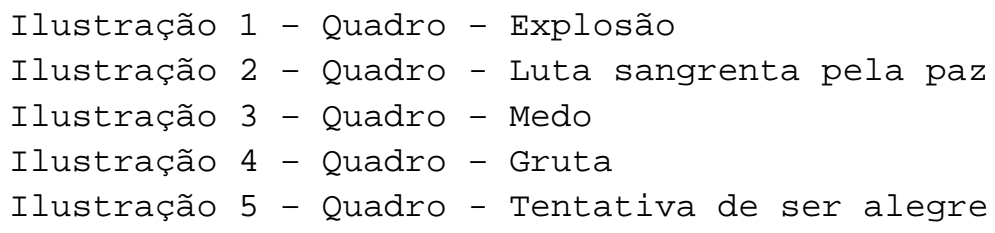

\section{Internet}

Disponível em:

http://br.geocities.com/claricegurgelvalente/14_pinturas.htm Consultado em 25 de agosto de 2006. 